Final version before publication; Ansbro, M. (2014) The Independent Inquiry into Child Sexual Exploitation in Rotherham, 1997-2013 Probation Journal 61(4) 429-432

\title{
The Independent Inquiry into Child Sexual Exploitation in Rotherham, 1997-2013
}

\section{Introduction}

Rotherham Borough Council commissioned Professor Jay and her team to complete a review of Child Sexual Exploitation (CSE) in 2013, after a recognition that children had been badly let down by local services. Professor Jay, a former social work adviser to the Scottish government, and author of other reviews (for example into Children's Services in Jersey) reported back in August 2014. Her report received extensive coverage, with headlines featuring the much cited estimate that 1,400 children had been victimised over the 15 year period.

\section{The Background}

A detailed chronology is provided; the creation of a local project called 'Risky Business' was the first acknowledgement that a substantial problem needed responding to. It seems to have established itself as a trusted resource. The effectiveness of this voluntary service was not matched by the statutory services. This was despite the issue of CSE being given a consistent profile in meetings held by the Council, Police and Children's Services. Papers were circulated, seminars and conferences held, 'task and finish' groups established, and a multi-agency Sexual Exploitation Forum was created in 2003. Action Plans were formulated, and from time to time some perpetrators were convicted and imprisoned (e.g. 2007 and 2008). At a practical level, nevertheless, children were left unprotected.

Professor Jay's chapter on inspections makes this point clearly. Over the 15 year period there could scarcely have been a day when some sort of inspection team was not on the premises. The majority were on general aspects of Children's Services, e.g. Social Services Inspectorate reports (1998 and 2003), Commission for Social Care Inspections (2004, 2007), OFSTED inspections in 2008, 2010, 2011 and 2012, to mention just the main events. Multi agency work to protect children in Rotherham received mixed results over the 15 year period, including two inadequate OFSTEDs, and a variety of criticisms aimed at every aspect of the process.

From around 2010 the focus on CSE moved up a gear, a reflection of key local events. In 2010 five men were imprisoned for grooming and abusing girls aged between 13 and 16 . In the same year there was the murder of child S, a 17 year old girl who was stabbed and dumped in a canal. Child $S$ was known to local agencies, and had been a victim of CSE since her early teens. She was mother to a young baby, and was murdered by current abuser when she revealed events to the families of the baby's father and her current abuser. The Serious Case Review that followed was 
heavily redacted, and caused The Times to allege a cover up, particularly about the Pakistani heritage of the men involved.

Inspections followed that were specifically on CSE. The LSCB commissioned a report by 'Justice Care Solutions' in 2010 on lessons learned regarding CSE - one theme it identified was that energy seemed to have been disproportionately targeted at governance and policy, at the expense of ensuring high quality work with children and families at the one-to-one level. This was followed by a report commissioned by Rotherham Local Authority in 2012 and carried out by Barnardo's on CSE, and a 2012 HMIC report on the Police response to CSE.

A chapter is devoted to the scale of CSE in Rotherham. Professor Jay is frank that her figure of 1,400 exploited children over the 15 year period is an estimate, extrapolated from the 66 case files they read in detail (a sample taken from the specialist CSE team, and other historic cases that were known to feature CSE), a list of 937 names of children 'associated with CSE' (this was provided by the Police and Children's Social Care) and names featuring on the minutes of Strategy meetings and the Sexual Exploitation Forum.

Detailed accounts are set out of 15 case histories, each one with similar themes. Grooming typically started by targeting children as young as 11 who were vulnerable through poor parental supervision and often more substantial neglect. Roughly a third of the children were looked after, and many more had social work involvement. They were children who would be particularly susceptible to offers of love, affection, alcohol, drugs, lifts, presents and an older 'boyfriend'. Once hooked in, this quickly turned into extreme sexual and physical abuse, by the groomer and other men. Often victims were compliant with what they perceived as a relationship, but any attempts not to cooperate, to end contact, or to make disclosures were met with threats of violence. Such threats (once reinforced by a dousing with petrol) were frequently carried out, including attacks on family members. The perpetrators motives seem to have changed over time; initially personal gratification was the driver, but the exploitation grew into a business opportunity, with children being trafficked for sexual purposes around various cities.

\section{Recurring Themes}

Arguably, three themes in particular have stirred up debate. The first is that for several years evidence about the scale and nature of the abuse was repeatedly suppressed. A report by an un-named Home Office Researcher met with a hostile response at the Home Office, and never saw the light of day - in fact the researcher was at one point suspended for gross misconduct. The Police commissioned research by drugs specialist Angie Heal, which made alarming connections between drugs, gangs, violent crime and CSE in Rotherham. The reports were widely distributed, but completely ignored.

The second theme was a perception of the victims that completely missed their vulnerability. South Yorkshire Police seem to have been particularly prone to classing victims as promiscuous and out of control. Until around 2007 they were 
often reluctant to become involved with children who were being exploited, and sometimes arrested the girls themselves for being drunk and disorderly or threatening them with arrest for wasting police time.

The third theme is that of the Pakistani ethnicity of the perpetrators, and this issue is complicated. It was clear to Professor Jay that there was nervousness around the issue, and interviewees believed that senior figures in the Council, the Police and Children's Social Care had, for instance, applied pressure to downplay this aspect. However, concrete examples were hard to come by. Whether real or apparent, the report is clear that the perception left front line practitioners confused about how to work in a way that would not be seen as racist. The Jay report is clear that 'race... should be tackled as an absolute priority if it is known to be a significant factor in the criminal activity of organised abuse in any local community'. The ethnicity of the victims is also examined, and the report is at pains to dispel the myth that all the victims of CSE are white. The point is made that disclosing is probably doubly difficult for Asian victims because they fear they will be ostracised by their own community.

\section{Lessons}

The report manages to acknowledge significant progress in the while avoiding any complacency. The Council is described as operating within a 'macho' and bullying 'culture' in the past, at times critical of the number of looked after children in Rotherham, and not prepared to consider the reality of CSE locally. However the report identifies real progress made by the council since 2009. The Police have now given the issue priority, and have for instance invested in training and in resourcing a joint CSE team. The Crown Prosecution Service is picked up for their unwillingness to prosecute alleged perpetrators in the past. The Director of Public Prosecutions revised guidelines for CSE in 2013 to develop prosecutors' understanding of vulnerability - it can indeed look like a child who is precociously sexualised, who uses alcohol and drugs, has a poor memory of events, who seems to be in a relationship with the perpetrator - and this will hopefully improve prosecutions. Taxi drivers featured heavily in accounts of CSE (the report writers were struck by local teenagers ubiquitous avoidance of any travel by taxi), and the licencing of drivers has proved a difficult issue to stay on top of. Schools are generally praised for noticing patterns (e.g. taxis picking up girls in lunch hour), and referring concerns.

The collective picture of Children's Social Care is one of much good practice in the face of overwhelming demands. She is in no doubt that thresholds for intervention were too high, and so children involved in CSE who were not subject to child protection procedures were often left unsupported. Children in residential units were particularly susceptible and staff were often unable to keep them safe. Prior to rofessor Jay's report Rotherham LSCB had collated the recommendations from other recent reports. Rather than repeat them, she concludes with 15 priority recommendations, most of which are addressed to the LSCB, Children's Social Care, and in particular the specialist CSE team. In particular she recommends that risk assessments are done on all victims of CSE, and that better long term support is provided, particularly to children who are placed out of the area. However she is 
concerned that spending cuts and staff shortages cast doubt on any prospect that these measures will be realised.

\section{Conclusion}

On this occasion the Probation Service gets hardly a mention. However practitioners in the criminal justice sector do have a part to play; if a male service user under supervision seemed to be consorting with young vulnerable females would we join the dots? If a 17 old female on an Unpaid Work Order was consistently being waited for by older men would we question the situation? What response would we give to a service user whose young teenager seemed to be out of control? Lastly, we need to ensure that the probation service is involved at the appropriate level in the Multiagency Sexual Exploitation panels that are becoming the multi-disciplinary forum for CSE work. 